\title{
Gender Differences in Clinicoepidemiological Features of Vitiligo: A Cross-Sectional Analysis
}

\author{
Sharmila Patil, ${ }^{1}$ Manjyot Gautam, ${ }^{1}$ Nitin Nadkarni, ${ }^{1}$ Neha Saboo, \\ Kiran Godse, ${ }^{1}$ and Maninder Singh Setia ${ }^{2}$ \\ ${ }^{1}$ Department of Dermatology, Dr. D. Y. Patil Medical College, Nerul, Navi Mumbai, India \\ ${ }^{2}$ Consultant Dermatologist and Epidemiologist, Mumbai, India
}

Correspondence should be addressed to Manjyot Gautam; manjyotgautam@gmail.com

Received 19 August 2013; Accepted 3 October 2013; Published 13 February 2014

Academic Editors: S. Dhar, C. Feliciani, and Y. M. Olumide

Copyright (C) 2014 Sharmila Patil et al. This is an open access article distributed under the Creative Commons Attribution License, which permits unrestricted use, distribution, and reproduction in any medium, provided the original work is properly cited.

Background. Vitiligo has important clinical and social consequences particularly in the pigmented skin. The present study was conducted to assess the differences in clinicoepidemiological presentation of vitiligo in males and females and to understand the factors associated with spread of vitiligo in them. Methods. This is a cross-sectional analysis of secondary clinical data of 168 vitiligo patients at a tertiary medical centre at Navi Mumbai. We used logistic regression models to estimate the association between gender and clinical characteristics of vitiligo and to evaluate the factors associated with spread of vitiligo. Results. There were no significant differences between the mean ages of males and females; however, males reported a longer duration of disease (6.9 (10.4) years) compared with females (4.9 (7.4) years). Males were significantly more likely to report a family history of vitiligo compared with females (adjusted OR (aOR): 16.87, 95\% CI: 2.16 to 131.69). Even though females were more likely to report spread of lesions, the association was not statistically significant (OR: 1.21, 95\% CI: 0.62 to 2.36). Discussion. The differences in the clinical presentations between genders highlight the need to understand the different factors (possibly genetic) that may play a part in the pathogenesis of this multifactorial disease in males and females.

\section{Introduction}

Vitiligo, a common dermatological disorder is characterized by milky-white depigmented macules devoid of identifiable melanocytes. Its incidence varies from 1 to $2 \%$ worldwide [1] and has been shown to be as high as $3-4 \%$ in India [2]. Vitiligo, often considered as a multifactorial disease [3], has important clinical and social consequences particularly in the pigmented skin. Though, the condition is cosmetically important, studies have also shown the association of vitiligo with several organ specific as well as systemic autoimmune diseases [4-6].

Numerous Indian studies have highlighted the clinical profile of vitiligo in various clinical settings [7-11]. Indeed, it has been reported that the mean duration of the disease in most of the patients was less than five years and vitiligo vulgaris was the most common clinical presentation $[8,10,12]$. Epidemiological studies have given a conflicting view of the occurrence of the condition in both genders. For instance, some studies have found that vitiligo was more common in males whereas others have found it to be more common in females $[5,8-10,12-16]$. And finally, some have found no difference in both genders $[1,2,4]$. Furthermore, studies have highlighted the stigma associated with vitiligo-particularly in women $[17,18]$.

Though, as stated above, studies have discussed few clinical and social aspects of vitiligo in men and women, few studies have differentiated the clinicepidemiological profile between both sexes. An understanding of the condition in both sexes will help us assess the similarities and differences of the clinical condition; this knowledge may help us devise strategies for clinical care of patients. Another issue that may help us in therapeutic decisions is the knowledge of factors associated with the spread of the disease in these patients.

Thus, with the above background, we conducted the following study to: (1) assess the differences in clinicoepidemiological presentation of vitiligo in males and females and (2) 


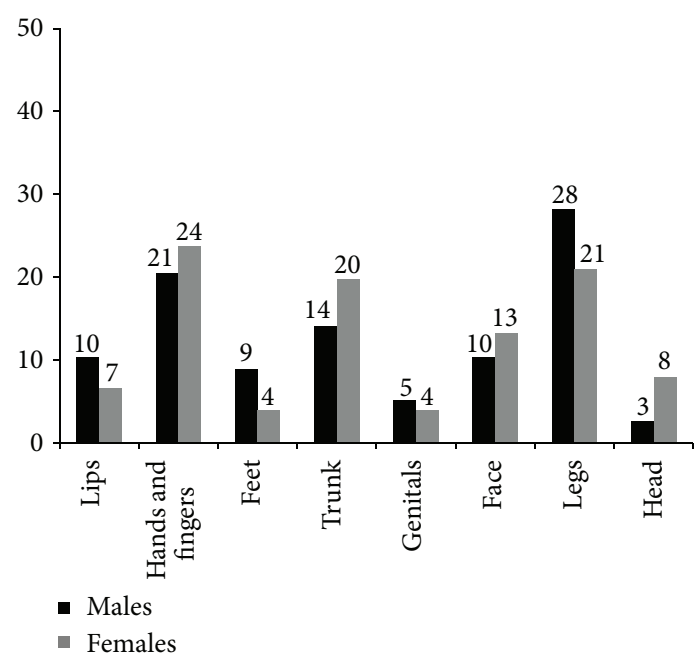

(a)

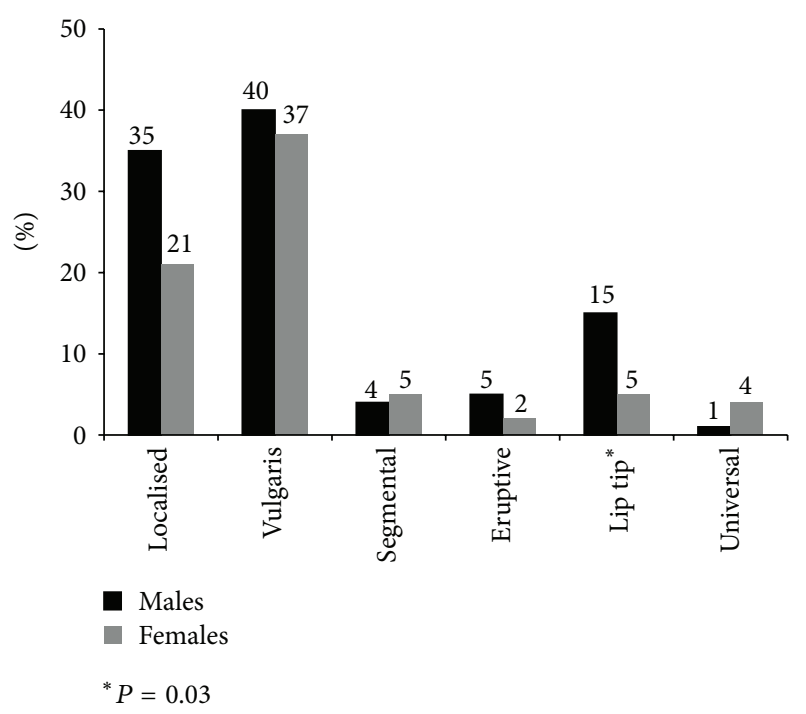

(b)

FIGURE 1: Figures showing (a) the site of initial lesion and (b) clinical presentation of vitiligo in 84 male and 84 female patients, Navi Mumbai.

to understand the factors associated with the spread of vitiligo in both males and females.

\section{Methods}

The present study is a cross-sectional analysis of secondary clinical data of 168 vitiligo patients over a period of two years (2007 to 2009).

2.1. Study Site. The study was conducted at the D. Y. Patil Medical College and Research Centre at Navi Mumbai, India. It is a tertiary care medical centre situated about 30 kilometres from Mumbai. The Dermatology Department of this Institute handles about 100 patients in the Outpatient Department daily and has various specialty clinics including the pigmentation and vitiligo clinic. Clinical information was recorded in all patients diagnosed with vitiligo. This included the baseline history, investigations, treatment given, and follow-up history of the patients.

2.2. Variables. Clinical baseline data of patients diagnosed with vitiligo were analysed for the present study. The parameters included for the analyses were demographic characteristics (age, sex, and occupation); age of onset of vitiligo and site of the initial lesion; clinical characteristics (type of vitiligo, site of the lesion, spread, and pigmentation); family history; and treatment history.

2.3. Data Analysis. Data were entered in MsExcel (Microsoft, Seattle, USA) and converted to Stata Version 11 (StataCorp, College Station, TX, USA) for further analysis.

We calculated proportions for categorical variables and means and standard deviations (SD) for linear variables. The differences in the proportions were assessed using the chisquare test and differences in the means were assessed using the $t$-test. Two main types of analysis were done to answer our research questions: (1) characteristics of vitiligo according to gender and (2) factors associated with spread of vitiligo.

We calculated the proportions of individuals according to their vitiligo characteristics separately for both genders; these proportions were compared using the chi-square test. We then used logistic regression models to assess the association between gender and vitiligo characteristics. The models were built in the following order: (1) unifactorial models and (2) age adjusted models. We also used logistic regression models to evaluate the factors associated with spread of vitiligo in these patients. These models were also built in the following sequence: (1) unifactorial models and (2) age and sex adjusted models.

The present analysis was approved by the Ethics Committee of our Institute. (Dr. D. Y. Patil Medical College Ethics Committee) for secondary data analysis.

\section{Results}

There were no significant differences between the mean ages (SD) of the male patients (28.4 (15.5) years) and female patients (30.0 (14.8) years). Most of the male patients were students $(35 \%)$, whereas a majority of females were housewives $(64 \%)$. We found that the mean age (SD) of onset was later in females (24.8 (15.3) years) compared with males (21.2 (16.6) years); this difference was, however, not statistically significant $(P=0.15)$. Males also reported a longer duration of disease (6.9 (10.4) years) compared with females (4.9 (7.4) years). There were no significant differences in site of initial lesion in male and females (Figure 1(a)). However, males were significantly more likely to have a clinical diagnosis of lip-tip vitiligo compared with females (23\% versus $2 \%$, $P<0.001$ ) (Figure 1(b)). We have described certain selected demographics and clinical characteristics in males and female patients in Table 1 and Figures 1(a) and 1(b). 
TABLE 1: Table showing the demographics and clinical characteristics of vitiligo in male and female patients, Navi Mumbai, India.

\begin{tabular}{|c|c|c|c|c|}
\hline Characteristics & $\begin{array}{c}\text { All } \\
n(\%)\end{array}$ & $\begin{array}{l}\text { Males } \\
n(\%)\end{array}$ & $\begin{array}{c}\text { Females } \\
n(\%)\end{array}$ & \\
\hline & $84(100)$ & $84(100)$ & $168(100)$ & \\
\hline \multicolumn{5}{|l|}{ Age (yrs) } \\
\hline Mean (SD) & $29.2(15.2)$ & $28.4(15.5)$ & $30.0(14.8)$ & 0.49 \\
\hline \multicolumn{5}{|l|}{ Occupation } \\
\hline Student & $46(31)$ & $27(35)$ & $19(26)$ & \\
\hline Housewife & $48(32)$ & $0(0)$ & $47(64)$ & \\
\hline Labour & $13(9)$ & $12(16)$ & $1(1)$ & \\
\hline Service & $25(17)$ & $20(26)$ & $6(8)$ & \\
\hline Others & $18(12)$ & $18(23)$ & $0(0)$ & $<0.001$ \\
\hline \multicolumn{5}{|c|}{ Age of onset (yrs) } \\
\hline Mean (SD) & $22.9(15.9)$ & $21.2(16.6)$ & $24.8(15.3)$ & 0.15 \\
\hline \multicolumn{5}{|c|}{ Duration of disease (yrs) } \\
\hline Mean (SD) & $5.9(9.0)$ & $6.9(10.4)$ & $4.9(7.4)$ & 0.17 \\
\hline \multicolumn{5}{|l|}{ Lesion spreading } \\
\hline Yes & $118(71)$ & $57(69)$ & $61(73)$ & \\
\hline No & $49(29)$ & $26(31)$ & $23(27)$ & 0.11 \\
\hline \multicolumn{5}{|c|}{ Family history of vitiligo } \\
\hline Yes & $15(9)$ & $14(17)$ & $1(1)$ & \\
\hline No & $151(91)$ & $68(83)$ & $83(99)$ & $<0.001$ \\
\hline \multicolumn{5}{|c|}{ Treatment taken for vitiligo } \\
\hline Yes & $82(49)$ & $41(49)$ & $41(49)$ & \\
\hline No & $85(51)$ & $42(51)$ & $43(51)$ & 0.93 \\
\hline \multicolumn{5}{|l|}{ Trichrome } \\
\hline Yes & $19(11)$ & $10(12)$ & $9(11)$ & \\
\hline No & $148(89)$ & $73(88)$ & $75(89)$ & 0.79 \\
\hline \multicolumn{5}{|l|}{ Pentachrome } \\
\hline Yes & $2(1)$ & $2(2)$ & $0(0)$ & \\
\hline No & 165 (99) & $81(98)$ & $84(100)$ & 0.15 \\
\hline \multicolumn{5}{|l|}{ Depigmented } \\
\hline Yes & $76(46)$ & $45(54)$ & $31(37)$ & \\
\hline No & $91(55)$ & $38(46)$ & $53(63)$ & 0.03 \\
\hline \multicolumn{5}{|l|}{ Hypopigmented } \\
\hline Yes & $8(5)$ & $3(4)$ & $5(6)$ & \\
\hline No & $159(95)$ & $80(96)$ & $79(94)$ & 0.48 \\
\hline \multicolumn{5}{|l|}{ Previtiligo } \\
\hline Yes & $2(1)$ & $1(1)$ & $1(1)$ & \\
\hline No & $165(99)$ & $82(99)$ & $83(99)$ & 0.99 \\
\hline \multicolumn{5}{|l|}{ Leucotrichia } \\
\hline Yes & $9(5)$ & $8(10)$ & $1(1)$ & \\
\hline No & $158(95)$ & $75(90)$ & $87(99)$ & 0.02 \\
\hline \multicolumn{5}{|c|}{ Follicular repigmentation } \\
\hline Yes & $5(3)$ & $5(6)$ & $0(0)$ & \\
\hline No & $162(97)$ & $78(94)$ & $84(100)$ & 0.02 \\
\hline \multicolumn{5}{|c|}{ Koebner's phenomenon } \\
\hline Yes & $21(13)$ & $19(23)$ & $2(2)$ & \\
\hline No & $146(87)$ & $64(77)$ & $82(98)$ & $<0.001$ \\
\hline
\end{tabular}


We found that older males were less likely to report with vitiligo in our clinic compared with older females. Males were significantly less likely to report onset of vitiligo in the age of 25 to 45 years compared with females in our population (odds ratio (OR): $0.38,95 \%$ confidence intervals (CI): 0.19 to 0.79 ). We also found that males were significantly more likely to report a family history of vitiligo compared with females (adjusted OR (aOR): 16.87, 95\% CI: 2.16, 131.69). Males were also significantly more likely to have depigmented lesions (aOR: 1.99, 95\% CI: 1.07 to 3.71) and leucotrichia (aOR: 8.72, 95\% CI: 1.06 to 71.53) compared with females. We also found that Koebner's phenomenon was more likely to be seen in male vitiligo patients compared with female patients (aOR: 12.14, 95\% CI: 2.73 to 54.09). We have described the unadjusted and adjusted association between sex and vitiligo characteristics in Table 2.

In our analysis, we found that patients who had presented to clinic after 45 years of age were less likely to report spread of lesions compared with patients who aged 12 years or less (OR: 0.51, 95\% CI: 0.14 to 1.83 ). Even though females were more likely to report spread of lesions, the association was not statistically significant (OR: 1.21, 95\% CI: 0.62 to 2.36). We found that the spread of vitiligo patches was more likely in patients who reported that the initial site of their lesions was on extremities (hands and fingers, legs, and feet) compared with those in whom the initial site of lesion was "head." Even after adjusting for age and sex, we found that patients who had a clinical diagnosis of vitiligo vulgaris were more likely to have spread of lesions compared with those who did not have this diagnosis (aOR: $2.44,95 \%$ CI: 1.16 to 5.17 ). We have described certain characteristics associated with the spread of vitiligo lesions (unadjusted and adjusted association between vitiligo and age and sex) in these patients in Table 3.

\section{Discussion}

The present cross-sectional analysis of 168 vitiligo patients provides important gender differences. Our sample of vitiligo patients had an equal proportion of males and females. Even though female patients were older compared with males, the latter reported a longer duration of disease. Males were significantly more likely to report a family history of vitiligo compared with females. They were also more likely to have a presentation with depigmented lesions, leucotrichia, and Koebner's phenomenon. The lesions which started on the extremities and those clinically diagnosed as vitiligo vulgaris were more likely to spread in our patients.

The clinical presentation of vitiligo had some similarities and some differences in both genders. For instance, the proportion of men and women presenting with vitiligo was similar in our sample. However, we did find that age of onset was slightly later in females compared with males; consequently, males also reported a longer duration of disease compared with females in our population. Women are more likely to report early to clinic due to cosmetic and social reasons; thus, they may have a shorter duration of disease compared with males. Compared with our study, others have reported a later age of onset of vitiligo $[7,19]$. Indeed, Howits and colleagues found the age of onset to be between 40 and 60
TABLE 2: Table showing the association between sex and characteristics of vitiligo in 168 patients in Navi Mumbai, India* .

\begin{tabular}{|c|c|c|}
\hline Characteristics & Unadjusted models & Adjusted models ${ }^{* *}$ \\
\hline \multicolumn{3}{|l|}{ Age (years) } \\
\hline $0-12$ & $1.00(0.43-2.31)$ & \\
\hline $12.1-25$ & $1.71(0.86-3.39)$ & \\
\hline $25.1-45$ & $0.82(0.44-1.52)$ & \\
\hline$>45$ & $0.62(0.26-1.48)$ & \\
\hline \multicolumn{3}{|l|}{ Age of onset (years) } \\
\hline $0-12$ & $1.81(0.91-3.57)$ & \\
\hline $12.1-25$ & $1.19(0.61-2.38)$ & \\
\hline $25.1-45$ & $0.38(0.19-0.79)$ & \\
\hline$>45$ & $1.32(0.47-3.74)$ & \\
\hline \multicolumn{3}{|l|}{ Site of initial lesion } \\
\hline Head & $0.31(0.06-1.57)$ & $0.32(0.06-1.63)$ \\
\hline Lips & $1.62(0.51-5.20)$ & $1.64(0.51-5.26)$ \\
\hline Hands and fingers & $0.83(0.39-1.78)$ & $0.86(0.40-1.88)$ \\
\hline Feet & $2.40(0.60-9.65)$ & $2.17(0.53-8.93)$ \\
\hline Trunk & $0.67(0.28-1.56)$ & $0.67(0.29-1.58)$ \\
\hline Genitals & $1.32(0.28-6.08)$ & $1.29(0.28-6.01)$ \\
\hline Face & $0.75(0.28-2.03)$ & $0.72(0.27-1.96)$ \\
\hline Legs & $1.47(0.70-3.09)$ & $1.46(0.69-3.06)$ \\
\hline \multicolumn{3}{|l|}{ Type of vitiligo } \\
\hline Localised & $1.97(0.94-4.15)$ & $1.97(0.94-4.17)$ \\
\hline Vulgaris & $1.12(0.60-2.11)$ & $1.14(0.61-2.13)$ \\
\hline Segmental & $0.75(0.16-3.46)$ & $0.71(0.15-3.29)$ \\
\hline Eruptive & $2.08(0.37-11.65)$ & $2.14(0.38-12.07)$ \\
\hline Lip-tip & $3.38(1.04-10.96)$ & $3.47(1.07-11.29)$ \\
\hline Universal & $0.33(0.03-3.23)$ & $0.34(0.03-3.32)$ \\
\hline Family history of vitiligo & $17.09(2.19->100)$ & $16.87(2.16-131.69)$ \\
\hline H/o spread & $0.82(0.42-1.61)$ & $0.83(0.43-1.62)$ \\
\hline Trichrome & $1.14(0.44-2.97)$ & $1.11(0.42-2.90)$ \\
\hline Depigmented & $2.02(1.09-3.76)$ & $1.99(1.07-3.71)$ \\
\hline Hypopigmented & $0.59(0.14-2.56)$ & $0.59(0.14-2.55)$ \\
\hline Previtiligo & $1.01(0.06-16.46)$ & $0.97(0.06-15.87)$ \\
\hline Leucotrichia & $8.85(1.08-72.46)$ & $8.72(1.06-71.53)$ \\
\hline Koebner's phenomenon & n $12.17(2.73-54.18)$ & $12.14(2.73-54.09)$ \\
\hline
\end{tabular}

${ }^{*}$ The reference for each model is sex: female. Thus, for family h/o vitiligo, the adjusted odds ratio is 16.87 (95\% confidence intervals 2.16 to 131.69 ) compared with females.

${ }^{* *}$ Adjusted for age.

years [19]. The proportion of cases in both genders has not shown any consistent pattern in the literature. While some authors have found a higher proportion in males, others have reported a higher proportion in females, and finally others have found no difference in the proportion between both genders $[1,2,4,5,8-10,12-16]$.

One important difference, however, between both genders was the type of vitiligo and a history of the condition in the family members. Indeed, we did find that males were more likely to report "hard-to-treat" type of vitiligo. They were more likely to have lip-tip type of vitiligo, leucotrichia, and depigmented lesions. Thus, males were more likely to 
TABLE 3: Table showing the association between vitiligo characteristics and spread of vitiligo in 168 patients, Navi Mumbai, India.

\begin{tabular}{|c|c|c|}
\hline Characteristics & Unadjusted models & Adjusted models* \\
\hline \multicolumn{3}{|l|}{ Age (years) } \\
\hline $0-12$ & Reference & \\
\hline $12.1-25$ & $0.38(0.12-1.20)$ & \\
\hline $25.1-45$ & $0.67(0.22-2.05)$ & \\
\hline$>45$ & $0.51(0.14-1.83)$ & \\
\hline \multicolumn{3}{|l|}{ Sex } \\
\hline Males & Reference & \\
\hline Females & $1.21(0.62-2.36)$ & \\
\hline \multicolumn{3}{|l|}{ Age of onset } \\
\hline $0-12$ & Reference & \\
\hline $12.1-25$ & $1.01(0.42-2.41)$ & \\
\hline $25.1-45$ & $1.32(0.53-3.29)$ & \\
\hline$>45$ & $1.29(0.36-4.64)$ & \\
\hline \multicolumn{3}{|l|}{ Site of initial lesion } \\
\hline Head & Reference & Reference \\
\hline Lips & $3.75(0.59-23.94)$ & $4.53(0.68-30.27)$ \\
\hline Hands and fingers & $4.62(0.91-23.43)$ & $5.11(0.99-26.43)$ \\
\hline Feet & $15.0(1.21->100)$ & $20.88(1.56->100)$ \\
\hline Trunk & $3.75(0.72-19.64)$ & $4.21(0.79-22.59)$ \\
\hline Genitals & $0.28(0.02-3.58)$ & $0.32(0.02-4.25)$ \\
\hline Face & $4.33(0.74-25.29)$ & $5.10(0.84-30.88)$ \\
\hline Legs & $7.38(1.41-38.42)$ & $8.96(1.64-49.02)$ \\
\hline \multicolumn{3}{|c|}{ Family history of vitiligo } \\
\hline No & Reference & Reference \\
\hline Yes & $1.75(0.47-6.51)$ & $2.04(0.53-7.90)$ \\
\hline \multicolumn{3}{|l|}{ Type of vitiligo } \\
\hline Localised & $0.50(0.23-1.10)$ & $0.50(0.22-1.10)$ \\
\hline Vulgaris & $2.42(1.15-5.12)$ & $2.44(1.16-5.17)$ \\
\hline Segmental & $2.57(0.30-21.94)$ & $2.59(0.30-22.23)$ \\
\hline Eruptive & $2.12(0.24-18.67)$ & $2.19(0.25-19.39)$ \\
\hline Lip-tip & $0.50(0.17-1.42)$ & $0.51(0.17-1.48)$ \\
\hline Universal & $0.41(0.06-2.96)$ & $0.38(0.05-2.80)$ \\
\hline \multicolumn{3}{|l|}{ Trichrome } \\
\hline No & Reference & Reference \\
\hline Yes & $1.63(0.52-5.21)$ & $1.67(0.52-5.35)$ \\
\hline \multicolumn{3}{|l|}{ Depigmented } \\
\hline No & Reference & Reference \\
\hline Yes & $0.82(0.42-1.60)$ & $0.85(0.43-1.68)$ \\
\hline \multicolumn{3}{|l|}{ Hypopigmented } \\
\hline No & Reference & Reference \\
\hline Yes & $0.39(0.09-1.65)$ & $0.38(0.09-1.61)$ \\
\hline \multicolumn{3}{|l|}{ Previtiligo } \\
\hline No & Reference & Reference \\
\hline Yes & $0.41(0.03-6.69)$ & $0.41(0.03-6.78)$ \\
\hline \multicolumn{3}{|l|}{ Leucotrichia } \\
\hline No & Reference & Reference \\
\hline Yes & $0.50(0.13-1.94)$ & $0.53(0.13-2.11)$ \\
\hline \multicolumn{3}{|c|}{ Follicular repigmentation } \\
\hline No & Reference & Reference \\
\hline Yes & $1.68(0.18-15.46)$ & $1.87(0.20-17.67)$ \\
\hline
\end{tabular}

TABle 3: Continued.

\begin{tabular}{lcc}
\hline Characteristics & Unadjusted models & Adjusted models* \\
\hline Koebner's phenomenon & & \\
No & Reference & Reference \\
Yes & $1.38(0.48-4.00)$ & $1.57(0.52-4.77)$ \\
\hline
\end{tabular}

${ }^{*}$ Adjusted for age and sex.

have lesions with poor therapeutic prognosis compared with females. One possible explanation for this feature could be that patients with treatment resistant vitiligo often present to tertiary care centres like our hospital. In such a situation, however, there should be no gender difference in presentation of treatment resistant cases. Thus, potentially, a higher proportion of men have treatment resistant cases. The proportion of patients who reported a family history of vitiligo was similar to the proportion reported in the literature $[15,20]$. An important finding, however, was the significantly higher proportion of men reporting a family history of vitiligo. Interestingly, Surekha and colleagues have also hypothesised that vitiligo may be $\mathrm{X}$-linked [16]. Thus, our clinicepidemiological findings may have a biological basis and should be explored in detail in the Indian population.

In our population, a majority reported that the lesions started on the extremities, a finding also reported by others authors $[13,21]$. One explanation could be that these sites, being trauma prone, may develop vitiligo lesions more easily in genetically predisposed persons as compared with other sites. Furthermore, lesions which started on the extremities were more likely to spread. Incidentally, we did not find any significant association between Koebner's phenomenon and spread of lesions. Thus, it is likely that the higher spread of lesions on the extremities may not be entirely explained by Koebnerization but may be due to the pathogenesis of the disease itself.

The study was not without its limitations. It was clinic based study; thus, some of the findings may not be representative of the general population. A population based sample will be useful to understand the exact prevalence of the condition and clinical features in the population at large. Since it was a secondary data analysis of data collected at the clinic, we did not have control over the variables and clinical information that we could analyse in the present manuscript. For instance, even though we had information on the history of similar lesions in the family members, we did not have further information about these members-as in were they siblings, male relatives, female relative, and so forth. Also, the family members were not examined by us. Thus, potentially, this is an important area for further exploration.

In spite of the above limitations, the study is a useful contribution to the clinicoepidemiological literature on vitiligo. We have stratified the analyses by gender to understand the similarities or differences between males and females. The differences in the clinical presentations between genders highlight the need to understand the different factors (possibly genetic) that may play a part in the pathogenesis of this multifactorial disease in males and females. 


\section{Conflict of Interests}

The authors declare that there is no conflict of interests regarding the publication of this paper.

\section{References}

[1] J.-B. Liu, M. Li, S. Yang et al., "Clinical profiles of vitiligo in China: an analysis of 3742 patients," Clinical and Experimental Dermatology, vol. 30, no. 4, pp. 327-331, 2005.

[2] S. Dave, D. Thappa, and M. Dsouza, "Clinical predictors of outcome in vitiligo," Indian Journal of Dermatology, Venereology and Leprology, vol. 68, no. 6, pp. 323-325, 2002.

[3] P. N. Behl, A. Agarval, and G. Srivastava, "Etiopathogenesis of vitiligo: are we dealing with an environmental disorder?" Indian Journal of Dermatology, Venereology and Leprology, vol. 65, no. 4, pp. 161-167, 1999.

[4] A. Alkhateeb, P. R. Fain, A. Thody, D. C. Bennett, and R. A. Spritz, "Epidemiology of vitiligo and associated autoimmune diseases in Caucasian probands and their families," Pigment Cell Research, vol. 16, no. 3, pp. 208-214, 2003.

[5] K. V. T. Gopal, G. R. Rama Rao, Y. H. K. Kumar, M. V. Appa Rao, P. Vasudev, and S. Srikant, "Vitiligo: a part of a systemic autoimmune process," Indian Journal of Dermatology, Venereology and Leprology, vol. 73, no. 3, pp. 162-165, 2007.

[6] R. A. Spritz, "The genetics of generalized vitiligo and associated autoimmune diseases," Pigment Cell Research, vol. 20, no. 4, pp. 271-278, 2007.

[7] S. Dogra, D. Parsad, S. Handa, and A. J. Kanwar, "Late onset vitiligo: a study of 182 patients," International Journal of Dermatology, vol. 44, no. 3, pp. 193-196, 2005.

[8] H. Shah, A. Mehta, and B. Astik, "Clinical and sociodemographic study of vitiligo," Indian Journal of Dermatology, Venereology and Leprology, vol. 74, no. 6, article 701, 2008.

[9] E. Shajil, D. Agrawal, K. Vagadia, Y. Marfatia, and R. Begum, "Vitiligo: clinical profiles in Vadodara, Gujarat," Indian Journal of Dermatology, vol. 51, no. 2, pp. 100-104, 2006.

[10] U. Suman Singh and S. S. Pandey, "Epidemiological profile of vitiligo in Northern India," Journal of Applied Pharmaceutical Science, vol. 1, no. 10, pp. 211-214, 2011.

[11] A. Kanwar, S. Dhar, and S. Kaur, "Vitiligo in children," Indian Journal of Dermatology, vol. 38, no. 3, pp. 47-52, 1993.

[12] S. Handa and I. Kaur, "Vitiligo: clinical findings in 1436 patients," Journal of Dermatology, vol. 26, no. 10, pp. 653-657, 1999.

[13] N. Al-Mutairi and A. K. Sharma, "Profile of vitiligo in Farwaniya region in Kuwait," Kuwait Medical College, vol. 38, pp. 128-131, 2006.

[14] S. O. Kovacs, "Vitiligo," Journal of the American Academy of Dermatology, vol. 38, no. 5, pp. 647-666, 1998.

[15] D. H. Nunes and L. M. H. Esser, "Vitiligo epidemiological profile and the association with thyroid disease," Anais Brasileiros de Dermatologia, vol. 86, no. 2, pp. 241-248, 2011.

[16] T. Surekha, M. Ishaq, K. P. Latha, P. H. Rao, and P. Jahan, "Do clinical variants of vitiligo involve $\mathrm{x}$-chromosomal gene(s) too?" Journal of Medical Sciences, vol. 8, no. 8, pp. 728-733, 2008.

[17] K. Ongenae, N. van Geel, S. de Schepper, and J.-M. Naeyaert, "Effect of vitiligo on self-reported health-related quality of life," British Journal of Dermatology, vol. 152, no. 6, pp. 1165-1172, 2005.
[18] M. A. Radtke, I. Schäfer, A. Gajur, A. Langenbruch, and M. Augustin, "Willingness-to-pay and quality of life in patients with vitiligo," British Journal of Dermatology, vol. 161, no. 1, pp. 134-139, 2009.

[19] J. Howitz, H. Brodthagen, M. Schwartz, and K. Thomsen, "Prevalence of vitiligo. Epidemiological survey on the Isle of Bornholm, Denmark," Archives of Dermatology, vol. 113, no. 1, pp. 47-52, 1977.

[20] V. N. Sehgal and G. Srivastava, "Vitiligo: compendium of clinico-epidemiological features," Indian Journal of Dermatology, Venereology and Leprology, vol. 73, no. 3, pp. 149-156, 2007.

[21] R. Reghu and E. James, "Epidemiological profile and treatment pattern of vitiligo in a tertiary care teaching hospital," International Journal of Pharmacy and Pharmaceutical Sciences, vol. 3, no. 2, supplement, pp. 137-141, 2011. 


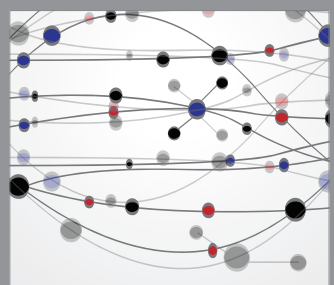

The Scientific World Journal
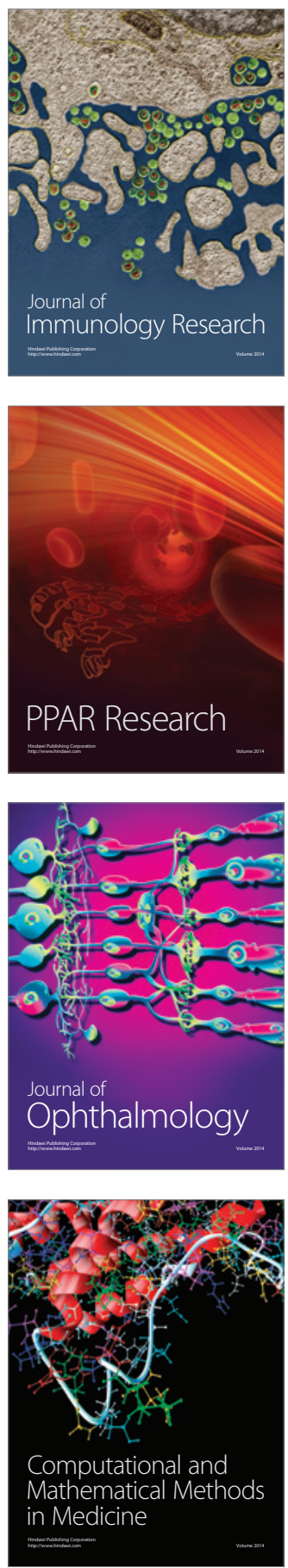

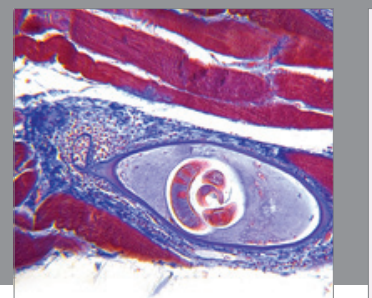

Gastroenterology

Research and Practice
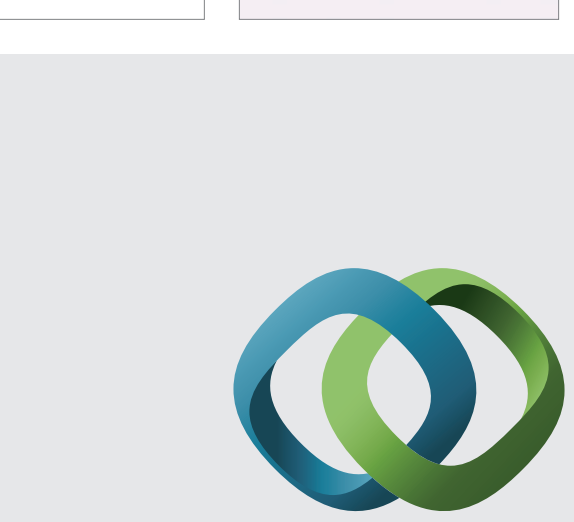

\section{Hindawi}

Submit your manuscripts at

http://www.hindawi.com
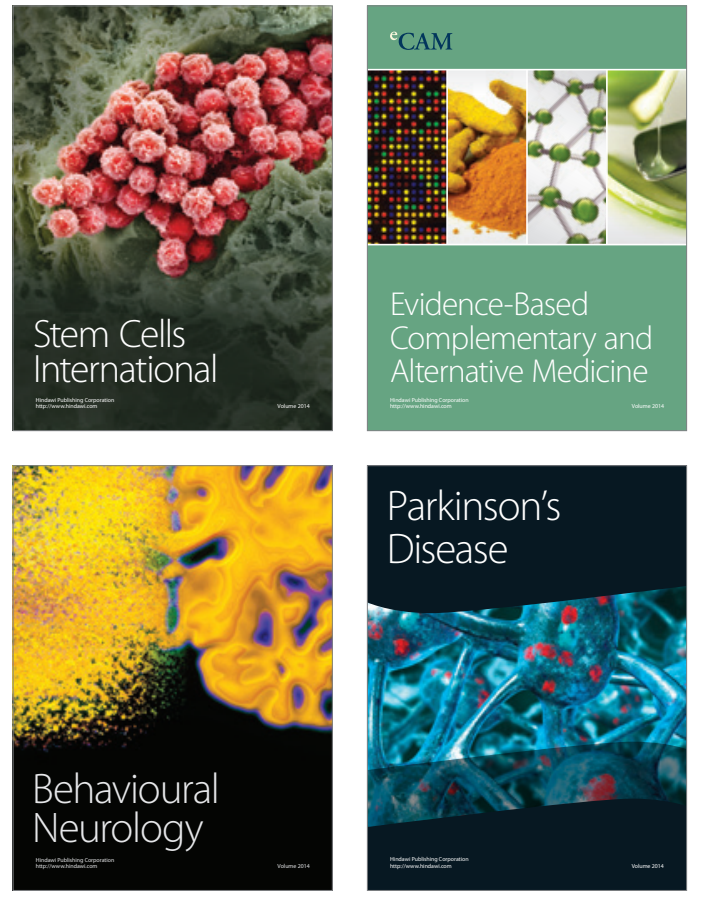
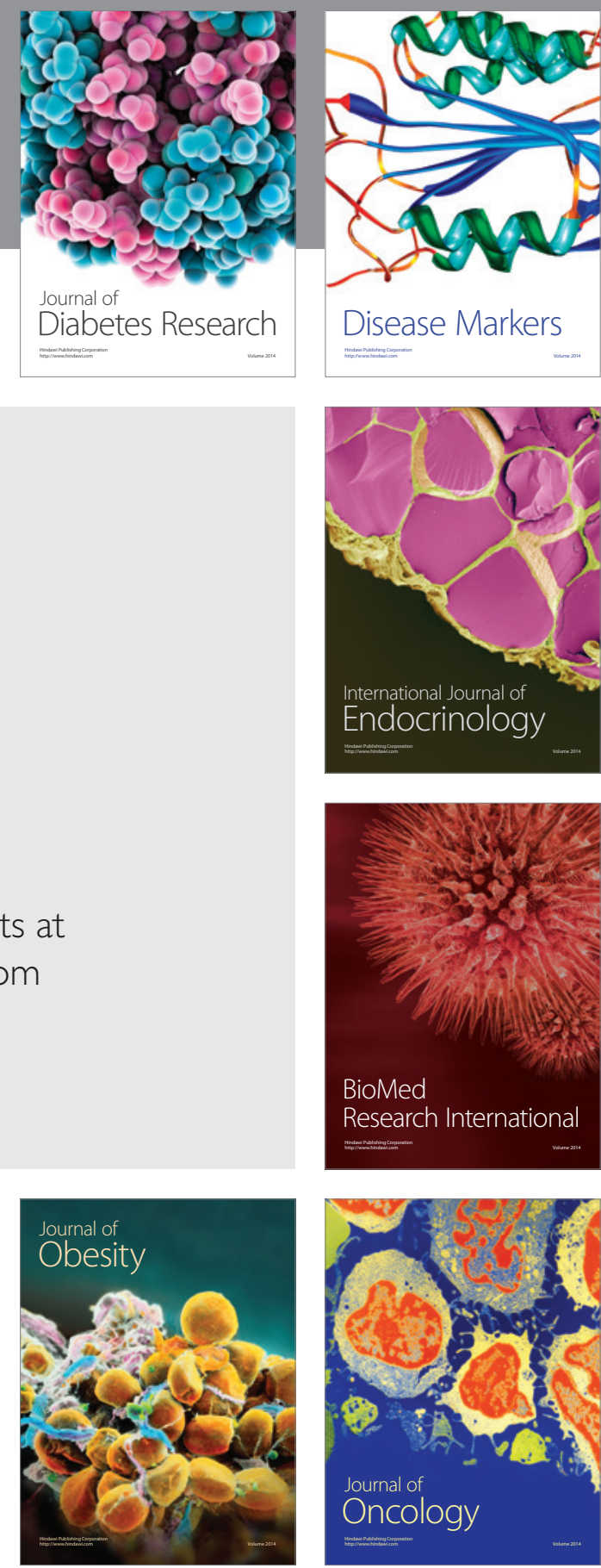

Disease Markers
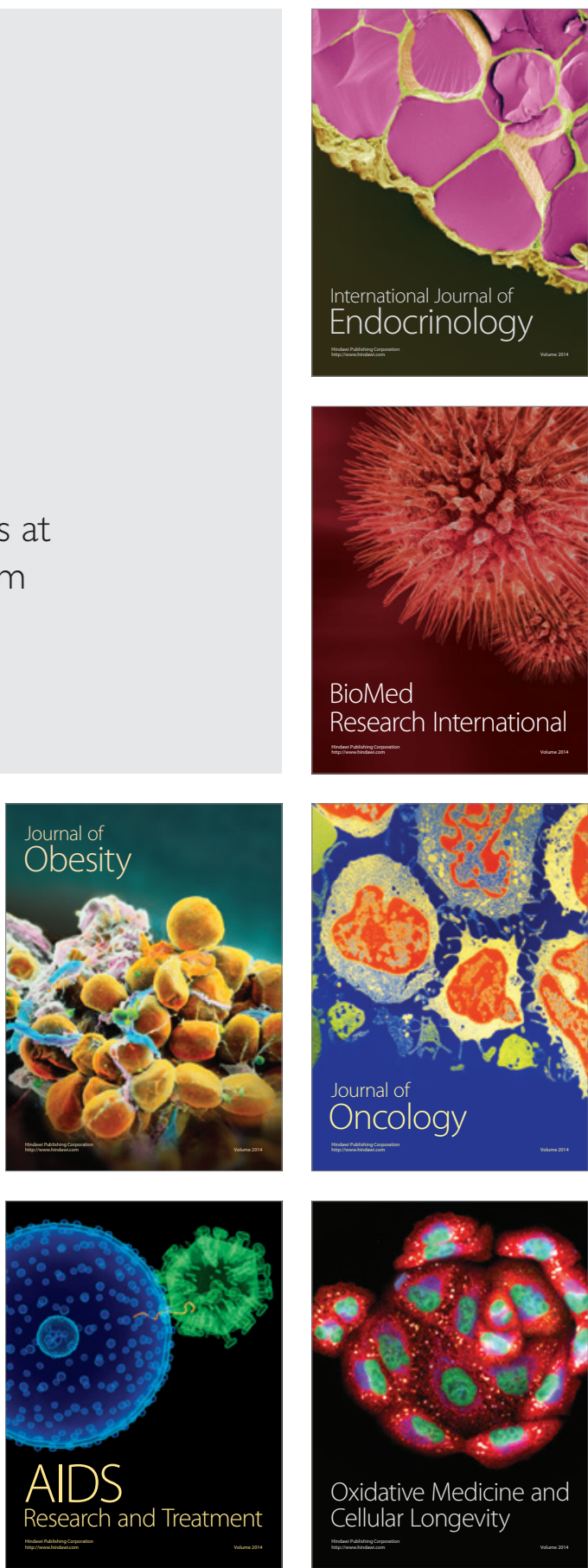